\title{
Amplify diverse voices
}

\author{
In this issue, we focus on justice, equity, diversity and inclusion in science.
}

$\mathrm{T}$ hree months ago, we published an editorial challenging ourselves and the scientific community to combat racism and make meaningful progress towards greater diversity and inclusion. Amongst the commitments we made, we said that we would report on progress in future editorials. Given the short time scale, what we can report is limited and we will provide another update in 6-12 months. However, we have assembled an issue that includes commentary on various aspects of the topic, so it seems appropriate to give a preliminary progress report.

In the earlier editorial, we said that we would strive towards quantitative monitoring of diversity, which would require infrastructure changes at the wider Springer Nature level. There have been discussions, in particular around the legal challenges of collecting these data, but there is no substantial progress at this stage. As an interim initiative, we suggested that authors might choose to self-identify to editors in their cover letters and we would add an extra layer of insight to those manuscripts. While we have made diversity more prominent in our thinking at all stages of the editorial process, so far there has been no uptake of this suggestion. Perhaps it has not yet been widely noticed, or perhaps we were mistaken in thinking it would be welcomed by researchers. That option certainly still stands, but we are also considering requiring a statement from all authors about diversity and inclusion, as suggested in a recent Correspondence in Nature. While we are not in a position yet to mandate it, we would certainly encourage it.

We also pledged to increase the number of underrepresented voices in our non-research content. Our commitment to use our Q\&A section specifically for this purpose is still a work in progress, with content currently in the pipeline; and while we have set up an anti-racism action channel on our community site, we are still in discussion over its first content from outside authors. We welcome anyone who would like to contribute - please just e-mail us. Internally, we are discussing our outreach and conference plans, with the added complication that COVID-19 has moved all of this activity online for the foreseeable future.

While our most important goal is to ensure diversity in all our content, not just that content which specifically discusses diversity, this issue represents a first step.

Miriti et al. respond directly to the Editorial, highlighting the need for specific recognition and action to promote the roles of Black women. They rightly note that we mentioned recruitment without also discussing retention, and they point out that we cited an example that was male-biased. These are important points and we should all refine our initiatives to ensure truly intersectional diversity and inclusion.

Schell et al. also note that editorials such as ours are a necessary but very small step on the long journey towards justice, equity, diversity and inclusion. They challenge white researchers to combat racism continually and consistently, and to work towards the genuine championing of Black excellence.

The ways in which we go about achieving these goals are varied and debateable. Even within the community of researchers who are genuinely committed to combating racism, there will be disagreements and no one group can speak for all. This is illustrated by the differing standpoints in a Comment by Tseng et al. and a Comment by Halsey et al. Tseng et al. offer advice to researchers who are Black, Indigenous or people of colour (BIPOC) that they argue is realistic and pragmatic, acknowledging the personal strains of being part of a minority in a white-dominated world. They recognize that others will have different lived experiences and may prefer a different approach. Halsey et al. assert that this approach is too compromising, and instead offer strategies that proactively challenge the structure of white-dominated science at all stages. While framed as advice for BIPOC researchers, this is important reading for other researchers too, to fully comprehend what they need to do and how problematic the status quo is. We do not downplay the genuine disagreement that underpins these two articles, but nevertheless hope that many readers will benefit greatly from both.
Another Comment, by Bailey et al., brings individuals' lived experiences, in this case in the context of fieldwork, to the fore. As part of a wider collaborative project, the authors are collating interviews with BIPOC researchers that painfully highlight the traumatic experiences they so often endure. Being in the field often exacerbates differences between white and non-white researchers. White researchers need to check their own expectations of how to behave in the field, and be strong allies when their colleagues experience racism.

These articles are written almost exclusively by researchers based in North America. This is not surprising given the origins and recent prominence of the Black Lives Matter movement, and the entrenched racism in the United States. However, it is important that we also discuss the problems experienced by minority researchers elsewhere and take action to champion them. Indeed, Halsey et al. explicitly call for researchers in other countries to build communities in the same way that they propose. It is also important that the voices of those researchers are heard directly, as authors and speakers, rather than merely discussed by those in a more comfortable majority position.

Elsewhere in this issue, two articles look at other aspects of diversity and inclusion in the context of international conferences. In a Perspective, Tulloch discusses the issue of sex and gender identity equity, examining the initiatives taken by conference organizers and their shortfallings. Location, safety, diverse programming, codes of conduct and financial barriers are amongst the factors that need to be considered. Organizers should also heed the point made in a Correspondence by Burnett et al. that diversity initiatives are too often marginalized in the conference schedule, severely compromising their effectiveness.

We hope that the articles in this issue can be a part of the ongoing journey towards justice, equity, diversity and inclusion both at this journal and within the wider community.

Published online: 28 September 2020 https://doi.org/10.1038/s41559-020-01324-9 